\title{
Randomized, double-blind, placebo- controlled clinical trial measuring the effect of a dietetic food on dermatologic scoring and pruritus in dogs with atopic dermatitis
}

Miguel Sánchez de Santiago', José Luis González Arribas', Yolanda Moral Llamas', Iveta Becvarova² and Hein Meyer ${ }^{2 *}$

\begin{abstract}
Background: Canine atopic dermatitis (AD) is a common condition that often requires multimodal therapy. Including a diet in the multimodal management of AD may reduce medication doses, saving pet owners money and reducing side effects. The objective of this randomized, double-blind, placebo-controlled clinical trial was to determine if a diet fortified in antioxidants, polyphenols, and omega-3 fatty acids can reduce the clinical signs of AD. Forty clientowned dogs with AD were enrolled in the study and assigned to either an enriched diet (diet B) or control diet (diet A) for 60-days. CADESI-4 index scores and owner-reported pruritus scores were measured periodically.

Results: Total CADESI-4 index scores for dogs eating diet B were lower on day 60 compared to baseline $(P=0.003)$. There was no statistical difference in scores for dogs eating diet A over a 60-day period. Diet B dogs had 25 and $49 \%$ reductions in CADESI-4 index scores on days 30 and 60 , respectively $(P=0.0007)$ while diet A had no change over the study period. When comparing the percent change in owner-reported pruritus scores, diet $B$ also performed better than diet A. By day 60 , owners feeding diet $B$ to their dogs reported a significant reduction $(P<0.0001)$ of $46.4 \%$ in itching, while those on diet A reported a $26.8 \%$ reduction, which was not statistically significant $(P=0.08)$.
\end{abstract}

Conclusions: These study results demonstrate feeding a diet enriched with ingredients to improve skin health and reduce inflammation improves the clinical signs of $A D$ in dogs.

Keywords: Canine, Atopy, Nutrition, Allergy, Dermatology, Veterinary, Diet

\section{Background}

Atopic dermatitis (AD) is a common cause of pruritus in dogs. The disease is multifactorial and defined as a "genetically predisposed inflammatory and pruritic allergic skin disease often associated with a production of immunoglobulin (Ig) E against environmental allergens" [1]. While the pathogenesis of AD is still unclear,

*Correspondence: hein_meyer@hillspet.com

${ }^{2}$ Hill's Pet Nutrition Inc., 400 Southwest Eighth Avenue, Topeka, KS 66603, USA

Full list of author information is available at the end of the article cutaneous inflammation from an aberrant immune response and defects in the epidermal barrier play key roles [2-4].

Atopic dermatitis often requires multimodal therapy incorporating allergy avoidance, immune-modulation, and enhancement of the epidermal barrier [5]. Several studies suggest oral supplementation with polyunsaturated fatty acids (PUFAs) reduces pruritus and can lower the dosages of cyclosporine and glucocorticoids required to control clinical signs [6-10]. PUFAs are thought to combat $\mathrm{AD}$ by enhancing epidermal barrier function, 
reducing inflammatory cell activation, and altering eicosanoid production $[5,11]$. In a study of healthy dogs, a diet supplemented with the omega-3 fatty acids docosahexaenoic acid (DHA) and eicosapentaenoic acid (EPA) reduced serum prostaglandin-E2 concentrations and interleukin-1 and interleukin-6 activity [12].

Dogs with AD have reduced continuity and thickness of the intracellular lipid lamella of the stratum corneum in non-lesional skin $[13,14]$. In addition, dogs with $\mathrm{AD}$ have lower ceramide levels within the SC compared to normal controls $[15,16]$. Evidence suggests oral supplementation with PUFAs can help mitigate some of these structural changes [14].

Polyphenols are naturally occurring compounds comprised of an aromatic ring with multiple phenol groups. Fruits and vegetables tend to have high polyphenol concentrations, and examples include curcumin, quercetin, resveratrol, and epigallocatechin gallate $[17,18]$. Polyphenols have been studied extensively for their anti-inflammatory and anti-neoplastic properties [19-21]. There is also evidence suggesting polyphenols may aid in the treatment of allergic diseases $[17,18]$. The mechanisms by which polyphenols affect allergic disease varies by class, but examples include formation of insoluble complexes with antigenic proteins to make them less allergenic [22], interference of dendritic cell function [23, 24], and reduction of $\mathrm{B}$ cell antibody and $\mathrm{T}$ cell cytokine production upon antigen re-exposure [18, 25-29]. Quercetin may also inhibit the release of mast cell inflammatory mediators and inhibit histamine synthesis [30-33].

Atopic dermatitis in both humans and dogs is linked to higher oxidative stress, likely due to a combination of lower plasma antioxidant concentrations and increased lipid peroxidation of cell membranes [34, 35]. The antioxidant vitamin $\mathrm{E}$ is crucial for preventing lipid peroxidation. Randomized, placebo-controlled clinical trials in humans and dogs noted improvement in clinical signs of AD with vitamin E supplementation [36, 37]. Vitamin C is another potent antioxidant and serum concentrations inversely correlate with clinical severity of AD in humans [38]. Intradermal concentrations of vitamin $C$ are also lower in people with AD [39].

Feeding a diet high in PUFA, polyphenols, and antioxidants would provide an easy adjunct to current $\mathrm{AD}$ treatments. A research abstract evaluating a diet enriched with these nutrients found lower levels IL12p40, MCP-1, and IL-2 in 25 dogs with AD after eating the diet for 28 days [40]. A previous unblinded, uncontrolled 8-week clinical trial in atopic dogs also found this type of enriched diet improved veterinarian Canine Atopic Dermatitis Extent and Severity Index (CADESI-03) scores and pet owner skin assessments [41]. The goal of this study is to verify those initial findings by investigating the effectiveness of a diet supplemented with vitamin $\mathrm{C}$ and $\mathrm{E}$, polyphenols, and PUFAs in a randomized, double-blinded, placebo-controlled fashion in client owned dogs with AD.

\section{Results}

Forty-three dogs were evaluated for the study. Three dogs were dismissed due to complete or partial response to a dietary elimination trial. Eighteen male (6 intact, 12 neutered) and 22 female dogs (5 intact, 17 spayed) with $\mathrm{AD}$ were enrolled over a 30 -month period and randomly assigned to diet A $(n=20)$ or diet B $(n=20)$. Completion rate for the study was $100 \%$. Diet groups did not differ by age $(\mathrm{A}=4.3 \mathrm{y}$ [1.0-9.0]; $B=5.0 y[2.0-11.0])$, body weight $(A=14.1 \mathrm{~kg}[1.7-$ $37.0] ; B=17.9 \mathrm{~kg}[3.9-32.6])$, or gender $(A=10 \mathrm{~F}, 10 \mathrm{M}$; $\mathrm{B}=12 \mathrm{~F}, 8 \mathrm{M})$. Age, breed, and gender of dogs assigned to each group are listed in Table 1 . Fifteen of 20 owners feeding diet A and 17 of 20 owners feeding diet B rated the palatability as excellent. Mean change in body weight did not differ between groups with diet A losing $0.20 \mathrm{~kg}$ and diet $B$ losing $0.14 \mathrm{~kg}$ throughout the course of the study (Table 1 ).

Total CADESI-4 index scores did not differ between groups on days zero, 30 or 60 . Scores were not significantly different between days zero, 30 and 60 in the diet A group, but were significantly lower on day 60 in the diet $\mathrm{B}$ group $(P=0.003)$ (Table 2$)$. When evaluating individual region scores of the CADESI-4 index, groups did not differ and no significant changes occurred between days. When evaluating the percentage change in CADESI-4 scores, diet $B$ had significant reductions of 25 and $49 \%$ on days 30 and 60 , respectively $(P=0.0007)$ while diet A had no change over study period. On day 60 , diet $B$ had a greater percentage change in CADESI-4 scores compared to diet A $(-48.5$ (B); -16.8 (A); $P=0.02$ ) (Table 3 ).

Owner-reported pruritus scores did not differ between groups and both groups saw statistically significant reductions by day $15(P<0.0001)$. Diet $\mathrm{B}$ group continued to have reductions in pruritus scores with day 60 being lower than days 0,15 , and 30 (Table 4). Overall, mean pruritus scores in diet $\mathrm{B}$ group went from 8.0 (range 4.0$10.0)$ to $3.5(0.0-9.0)$ over the course of the study. When comparing the percent of change in owner-reported pruritus scores, diet $\mathrm{B}$ also performed better than diet $\mathrm{A}$. By day 60 , owners of dogs fed diet $B$ reported a significant reduction $(P<0.0001)$ of $46.4 \%$ in itching, while those on diet A reported a $26.8 \%$ reduction, which was not statistically significant $(P=0.08)$. The percentage change in pruritus between groups was not statistically different on corresponding days (Table 5). 
Table 1 Characteristics of Dogs Enrolled in Study

\begin{tabular}{|c|c|c|c|c|c|c|}
\hline Dog ID & AGE (years) & SEX & $\begin{array}{l}\text { START WEIGHT } \\
(\mathrm{kg})\end{array}$ & END WEIGHT (kg) & BREED & GROUP \\
\hline 1 & 2 & FS & 5.4 & 5.6 & Mixed & A \\
\hline 2 & 1 & FS & 10.9 & 11.3 & French bulldog & A \\
\hline 3 & 8 & M & 7.3 & 7.4 & Maltese & A \\
\hline 4 & 3 & MN & 30.0 & 35.0 & Mixed & A \\
\hline 5 & 2 & MN & 8.6 & 8.5 & Pinscher & A \\
\hline 6 & 5 & FS & 9.2 & 9.6 & Schnauzer mini & A \\
\hline 7 & 8 & M & 37 & 35.1 & Labrador retriever & A \\
\hline 8 & 7 & $F$ & 1.7 & 1.6 & Yorkshire terrier & A \\
\hline 9 & 9 & FS & 3.3 & 3.1 & Yorkshire terrier & A \\
\hline 10 & 6 & $\mathrm{MN}$ & 14.1 & 13.8 & French bulldog & A \\
\hline 11 & 2 & FS & 26.3 & 25.4 & Spanish greyhound & A \\
\hline 12 & 4 & M & 36.0 & 34.3 & Golden retriever & A \\
\hline 13 & 3 & FS & 28.0 & 28.5 & Mixed & A \\
\hline 14 & 4 & $\mathrm{~F}$ & 13.6 & 13.8 & French bulldog & A \\
\hline 15 & 6 & FS & 12.7 & 14.1 & French bulldog & A \\
\hline 16 & 5 & M & 17.8 & 16.8 & Mixed & A \\
\hline 17 & 2 & $\mathrm{MN}$ & 33.0 & 34.0 & German shepherd & A \\
\hline 18 & 1 & FS & 27.4 & 27.8 & Dobermann & A \\
\hline 19 & 6 & MN & 14 & 14.3 & Mixed & A \\
\hline 20 & 4 & $\mathrm{MN}$ & 28 & 28.9 & American Staffordshire & A \\
\hline 21 & 2 & FS & 8 & 8.3 & West highland white terrier & $\mathrm{B}$ \\
\hline 22 & 2 & FS & 28.8 & 27.0 & Labrador retriever & $\mathrm{B}$ \\
\hline 23 & 11 & M & 17.6 & 16.4 & Beagle & B \\
\hline 24 & 2 & M & 32.6 & 32.6 & American Staffordshire & B \\
\hline 25 & 3 & FS & 11 & 11.1 & French bulldog & $\mathrm{B}$ \\
\hline 26 & 11 & M & 16.9 & 17.5 & Beagle & B \\
\hline 27 & 6 & FS & 19.7 & 19.9 & American Staffordshire & B \\
\hline 28 & 3 & FS & 3.9 & 4.1 & Yorkshire terrier & B \\
\hline 29 & 5 & FS & 29.3 & 29.4 & Boxer & B \\
\hline 30 & 9 & $\mathrm{~F}$ & 25.3 & 23.5 & Labrador retriever & B \\
\hline 31 & 6 & FS & 32.4 & 33.2 & Labrador retriever & B \\
\hline 32 & 4 & $\mathrm{MN}$ & 18.2 & 19.0 & French bulldog & B \\
\hline 33 & 8 & $\mathrm{MN}$ & 7.2 & 7.4 & West highland white terrier & B \\
\hline 34 & 6 & FS & 12.7 & 13.4 & French bulldog & B \\
\hline 35 & 5 & M & 13 & 12.6 & Andalusian bodeguero & B \\
\hline 36 & 4 & FS & 26 & 28.5 & Gos D’atura Catalá & B \\
\hline 37 & 3 & FS & 26.8 & 29.2 & Siberian husky & B \\
\hline 38 & 7 & $\mathrm{~F}$ & 4.9 & 4.7 & Mixed & B \\
\hline 39 & 6 & $\mathrm{MN}$ & 17 & 15.9 & Mixed & B \\
\hline 40 & 4 & $\mathrm{MN}$ & 22 & 22.4 & Mixed & B \\
\hline
\end{tabular}

Description of dogs enrolled in study. $F$ intact female, $F S$ female spayed, $M$ intact male, $M N$ male neutered

\section{Discussion}

Results of this randomized, double-blind, placebo-controlled clinical trial demonstrate significant improvement in CADESI-4 scores and owner-reported pruritus scores for dogs consuming a diet high in antioxidants, polyphenols, EPA, and DHA (diet B). This study also supports the findings of a previous uncontrolled clinical trial evaluating the same diet in dogs with $\mathrm{AD}$ [41]. The improvements seen in studies of diet B can be attributed to the diet's functional ingredients. Research has demonstrated increased consumption of omega-3 fatty acids improves clinical signs associated with canine $\mathrm{AD}[6,9]$. The 
Table 2 Total CADESI-4 index scores recorded by veterinarians during the study period

\begin{tabular}{llll}
\hline Day & Diet A & Diet B & Pvalue $^{*}$ \\
\hline 0 & $10.5(2.0-44.0)^{\mathrm{a}}$ & $14.5(4.0-29.0)^{\mathrm{a}}$ & 0.3020 \\
30 & $8.5(1.0-24.0)^{\mathrm{a}}$ & $10.5(1.0-30.0)^{\mathrm{ab}}$ & 0.2818 \\
60 & $7.5(1.0-25.0)^{\mathrm{a}}$ & $7.0(0.0-41.0)^{\mathrm{b}}$ & 0.7602 \\
Pvalue $^{\dagger}$ & 0.0270 & 0.0034 & \\
\hline
\end{tabular}

Total CADESI-4 index scores recorded by veterinarians during the study period. Scores did not differ between groups at any time point. Scores were significantly lower for diet B on day 60 . There was no difference between days in diet A. Data are reported as median (range). ${ }^{*} P$ value to compare groups within each day. $+P$ value to compare days within each group. Note that for $\operatorname{diet} A$, statistical significance disappeared after adjusting for multiple comparisons. Within each column, days with different superscript letters differ from each other $(p<0.05)$

Table 3 Percent change in CADESI-4 index scores recorded by veterinarians during the study period

\begin{tabular}{llll}
\hline Day & Diet A & Diet B & P value* \\
\hline 30 & $-10.7(-76.9-125.0)$ & $-25.0(-87.5-66.7)$ & 0.4976 \\
60 & $-16.8(-87.5-275.0)$ & $-48.5(-100.0-57.7)$ & 0.0212 \\
Pvalue $^{\dagger}$ & 0.1701 & 0.0007 & \\
\hline
\end{tabular}

Percent change in total CADESI-4 index scores recorded by veterinarians during the study period. Diet $B$ had significant reductions of 25 and $48.5 \%$ on days 30 and 60 while diet $A$ had no change. On day 60 , diet $B$ had a greater percentage change in CADESI-4 scores compared to diet A. Data are reported as median (range).* $P$ value to compare groups within each day. $+P$ value to compare days within each group

Table 4 Owner-reported pruritus scores

\begin{tabular}{llll}
\hline Day & Diet A & Diet B & P value* $^{*}$ \\
\hline $\mathbf{0}$ & $8.0(6.0-10.0)^{\mathrm{a}}$ & $8.0(4.0-10.0)^{\mathrm{a}}$ & 0.8981 \\
$\mathbf{1 5}$ & $7.0(2.0-10.0)^{\mathrm{b}}$ & $6.5(2.0-9.0)^{\mathrm{b}}$ & 0.4464 \\
$\mathbf{3 0}$ & $5.0(1.0-9.0)^{\mathrm{bc}}$ & $4.0(1.0-10.0)^{\mathrm{bc}}$ & 0.6808 \\
$\mathbf{4 5}$ & $5.5(1.0-8.0)^{\mathrm{bcd}}$ & $4.0(1.0-8.0)^{\mathrm{cd}}$ & 0.1872 \\
$\mathbf{6 0}$ & $6.0(1.0-10.0)^{\mathrm{bcd}}$ & $3.5(0.0-9.0)^{\mathrm{d}}$ & 0.1518 \\
$\boldsymbol{P}^{\text {value }}{ }^{\dagger}$ & $<0.0001$ & $<0.0001$ & \\
\hline
\end{tabular}

Owner-reported pruritus scores assessed on a scale of zero to 10 where zero is no itching and 10 is extreme itching [42]. Scores did not differ between groups and both groups saw statistically significant reductions by day 15 . Diet B group continued to have reductions in pruritus scores with day 60 being lower than days 0,15 , and 30 . Data are reported as median (range).* $P$ value to compare groups within each day. $+P$ value to compare days within each group. Within each column, days with different superscript letters differ from each other $(p<0.05)$

amount of EPA and DHA in diet B is similar to dosages used in these other clinical trials $(1.35 \mathrm{~g} / 1000 \mathrm{kcal})$ when dogs meet daily energy requirements as estimated by the National Research Council (95-180 × kg0.75) [43]. The antioxidant vitamin $\mathrm{E}$ has also demonstrated effectiveness in lowering AD CADESI scores when supplemented at levels similar to diet B 37. While studies evaluating the
Table 5 Percent change in owner-reported pruritus scores

\begin{tabular}{llll}
\hline Day & Diet A & Diet B & P value* \\
\hline $\mathbf{1 5}$ & $-12.5(-77.8-33.3)$ & $-21.1(-50.0-16.7)^{\mathrm{a}}$ & 0.4405 \\
$\mathbf{3 0}$ & $-31.0(-87.5-50.0)$ & $-35.4(-88.9-14.3)^{\mathrm{a}}$ & 0.7616 \\
$\mathbf{4 5}$ & $-31.0(-87.5-33.3)$ & $-42.9(-90.0-0.0)^{\mathrm{bc}}$ & 0.2607 \\
$\mathbf{6 0}$ & $-26.8(-88.9-66.7)$ & $-46.4(-100.0-0.0)^{\mathrm{c}}$ & 0.1529 \\
Pvalue $^{\dagger}$ & 0.0815 & $<0.0001$ & \\
\hline
\end{tabular}

Percent change in owner-reported pruritus scores. By day 60, diet B owners reported a significant reduction of $46.4 \%$ in itching. Data are reported as median (range). ${ }^{*} P$ value to compare groups within each day. ${ }^{\dagger} P$ value to compare days within each group. Within each column, days with different superscript letters differ from each other $(p<0.05)$

role of polyphenols in canine $\mathrm{AD}$ are lacking, research utilizing rodent models of $\mathrm{AD}$ suggest resveratrol and quercetin can mitigate clinical signs and improve skin health $[44,45]$.

The control diet chosen in this study provides a similar macronutrient profile to the test diet while being lower in key nutrients ( $\mathrm{n}-3$ fatty acids and vitamin $\mathrm{E}$ ) and functional ingredients high in polyphenols and antioxidants. While the total n-3 fatty acid concentration of the test diet was nearly 6 times higher than the control, the composition of n-3 fatty acids in the control diet was not measured. Although comparing individual nutrient changes in a clinical trial is ideal, for cost and efficiency the authors felt it was reasonable to initially evaluate the composite effects of test diet to determine efficacy in AD. Additional studies assessing individual ingredient and nutrient effects would be beneficial.

Owner-reported pruritus and CADESI-4 scores trended lower over time in both diet groups. Some of this improvement may be attributed to a placebo effect and/ or treatment with oclacitinib and parasite preventatives. However, diet $\mathrm{B}$ owners noted $46 \%$ reduction in pruritus while the $27 \%$ reduction noted by diet A owners was not statistically different from baseline. The CADESI-4 scores were not statistically lower than baseline for diet A, but diet B showed improved scores on day 60 with a drop of almost $50 \%$. The dramatic improvement in both veterinarian and owner-reported $\mathrm{AD}$ scores implies a diet effect, rather than improvement from medical therapy alone. In conclusion, this clinical trial demonstrates feeding a diet enriched with ingredients to improve skin health and reduce inflammation improves the clinical signs of AD in dogs.

\section{Conclusion}

Compared to control, a diet enriched with ingredients to improve skin health and reduce inflammation improve the clinical signs of AD in dogs as measured by pet owners and veterinarians. 


\section{Methods}

This prospective study was approved by the ethics committee of Complutense University. Dogs with AD examined at our veterinary hospital were included in this study. Dogs were diagnosed with AD based on history, clinical signs, and fulfillment of Favrot's criteria [46]. Patients also had to be free from ectopic parasites as determined by deep and superficial skin scraping and have received parasite preventative medications for at least 2 months prior to enrollment. Primary pyodermas were excluded through tape cytology and culture of pustules if present. Once ectopic parasites and pyodermas were excluded, patients underwent an 8-week dietary elimination trial with a hydrolyzed protein diet to ruleout food allergic dermatitis (Hill's Prescription Diet ${ }^{\mathrm{TM}} \mathrm{z} /$ $\mathrm{d}^{\mathrm{TM}}$, Hill's Pet Nutrition, Topeka, KS, USA).

Oclacitinib (Apoquel ${ }^{\circledR}$, Zoetis, Parsippany, NJ, USA) treatment was not permitted before enrollment, but once admitted to the study oclacitinib was initiated at a dose of $0.4-0.6 \mathrm{mg} / \mathrm{kg} /$ every $12 \mathrm{~h}$ for 14 days; followed by a maintenance dose of $0.4-0.6 \mathrm{mg} / \mathrm{kg}$ every $12 \mathrm{~h}$ until the end of the study. This treatment was initiated in all dogs since dietary intervention was viewed as an adjunct, rather than replacement, to medical therapy, and oclacitinib is considered the standard of care. Patients were also encouraged to wear a fly and flea preventative collar throughout the study but were prohibited from giving oral parasite preventatives. Owners were not permitted to give their dogs dietary supplements, treats, or topical medications during the treatment period.

Dogs meeting enrollment criteria were randomly assigned to a control diet A (Purina Proplan ${ }^{\mathrm{TM}}$ Opti Nutrition Adult ${ }^{\mathrm{TM}}$ Medium dry, Nestlé Purina, St. Louis, MO, USA) or test diet B (Hill's Prescription Diet ${ }^{\mathrm{TM}}$ Derm Defense $^{\mathrm{TM}}$ dry, Hill's Pet Nutrition, Topeka, KS, USA) for 60-days (Table 6). Diet A ingredients included dehydrated poultry protein, wheat, maize, chicken, animal fat, dried beet pulp, soya meal, maize grits, rice, digest, gluten, minerals, and fish oil. Diet B ingredients included maize, brewer's rice, chicken and turkey meal, dried whole egg, soybean oil, flaxseed oil, animal fat, dried beet pulp, fish oil, minerals, vitamins, taurine, beta-carotene, and mixed tocopherols. Diet B also contained an antioxidant blend with rosemary, green tea, citrus pulp, and vitamin C. (Table 7). The control diet was chosen because it is a commonly used and widely available dog food in Spain. The control diet also had a similar macronutrient profile to the test diet, while containing lower concentrations of omega-3 fatty acids, polyphenols, and the antioxidants vitamin $\mathrm{C}$ and $\mathrm{E}$. Both dog owners and investigators were blinded to the diets. Dog owners were provided feeding amounts in grams for each diet based on their pet's current body weight. They were also instructed to adjust the food amount as necessary to maintain optimal weight.

Table 6 Nutrient composition of study diets

\begin{tabular}{|c|c|c|c|c|}
\hline Nutrient & Diet A DMB & Diet A per $1000 \mathrm{kcal}$ & Diet B DMB & Diet B Per $1000 \mathrm{kcal}$ \\
\hline Crude protein & $25.0 \%$ & $62 \mathrm{~g}$ & $22.7 \%$ & $55 \mathrm{~g}$ \\
\hline Crude fat & $15.0 \%$ & $37 \mathrm{~g}$ & $17.0 \%$ & $41 \mathrm{~g}$ \\
\hline Nitrogen-free extract & $40.5 \%$ & $100 \mathrm{~g}$ & $53.4 \%$ & $130 \mathrm{~g}$ \\
\hline Crude fiber & $2.5 \%$ & $6.2 \mathrm{~g}$ & $1.6 \%$ & $4 \mathrm{~g}$ \\
\hline Linoleic acid & $\mathrm{n} / \mathrm{a}$ & $\mathrm{n} / \mathrm{a}$ & $4.59 \%$ & $11.2 \mathrm{~g}$ \\
\hline alpha-Linolenic acid & $\mathrm{n} / \mathrm{a}$ & $\mathrm{n} / \mathrm{a}$ & $1.11 \%$ & $2.7 \mathrm{~g}$ \\
\hline $\begin{array}{l}\text { Eicosapentaenoic + Docosahexae- } \\
\text { noic acid }\end{array}$ & $\mathrm{n} / \mathrm{a}$ & $\mathrm{n} / \mathrm{a}$ & $0.56 \%$ & $1.38 \mathrm{~g}$ \\
\hline Eicosapentaenoic acid & $\mathrm{n} / \mathrm{a}$ & $\mathrm{n} / \mathrm{a}$ & $0.33 \%$ & $0.81 \mathrm{~g}$ \\
\hline Docosahexaenoic acid & $\mathrm{n} / \mathrm{a}$ & $\mathrm{n} / \mathrm{a}$ & $0.23 \%$ & $0.57 \mathrm{~g}$ \\
\hline Total n-6 fatty acids & $2.6 \%$ & $6.4 \mathrm{~g}$ & $4.76 \%$ & $11.6 \mathrm{~g}$ \\
\hline Total n-3 fatty acids & $0.3 \%$ & $0.74 \mathrm{~g}$ & $1.81 \%$ & $4.42 \mathrm{~g}$ \\
\hline Zinc & $187 \mathrm{mg} / \mathrm{kg}$ & $0.045 \mathrm{~g}$ & $267 \mathrm{mg} / \mathrm{kg}$ & $0.065 \mathrm{~g}$ \\
\hline Vitamin A & $20,710 \mathrm{IU} / \mathrm{kg}$ & $5123 \mathrm{IU}$ & $10,638 \mathrm{IU} / \mathrm{kg}$ & $2590 \mathrm{IU}$ \\
\hline Vitamin E & $473 \mathrm{mg} / \mathrm{kg}$ & $0.12 \mathrm{~g}$ & $874 \mathrm{mg} / \mathrm{kg}$ & $0.21 \mathrm{~g}$ \\
\hline Vitamin C & $70 \mathrm{mg} / \mathrm{kg}$ & $0.017 \mathrm{~g}$ & $98 \mathrm{mg} / \mathrm{kg}$ & $0.024 \mathrm{~g}$ \\
\hline Beta carotene & $\mathrm{n} / \mathrm{a}$ & & $1.6 \mathrm{mg} / \mathrm{kg}$ & $0.4 \mathrm{mg}$ \\
\hline Energy (kcal) & $4042 / \mathrm{kg}$ & $3840 / \mathrm{kg}$ as fed & $4110 / \mathrm{kg}$ & $3760 / \mathrm{kg}$ as fed \\
\hline Energy (kJ) & $16,911 / \mathrm{kg}$ & $16,066 / \mathrm{kg}$ & $17,200 / \mathrm{kg}$ & $15,730 / \mathrm{kg}$ \\
\hline
\end{tabular}

Legend: Nutrient composition of test diets on a dry matter basis (DMB) and per $1000 \mathrm{kcal}$ basis 
Table 7 Classification of major functional dietary ingredients in $\operatorname{diet} \mathrm{B}$

\begin{tabular}{lll}
\hline $\begin{array}{l}\text { Polyunsaturated Fatty } \\
\text { Acids }\end{array}$ & Polyphenol & Antioxidant \\
\hline Soybean oil & Flaxseed & Green tea \\
Flaxseed & Brewer's rice & Brewer's rice \\
Fish oil & Rosemary & Dried beet pulp \\
& Green tea & Rosemary \\
& Citrus pulp & Vitamin E \\
& & Vitamin C \\
& & Beta-carotene
\end{tabular}

Legend: Classification of functional dietary ingredients in test diet B [47-50]

The severity of $\mathrm{AD}$ was assessed by a single investigator who was blinded to diet assignment. Assessments occurred at days zero, 30, and 60 using the CADESI-4 index which rates the severity and extent of the skin lesions (erythema, lichenification and alopecia/excoriation) on a scale from 0 to 3 at 20 anatomic locations [42]. CADESI- 4 scores of less than 8 are considered normal [42]. Owners also assessed intensity of their pet's pruritus on days zero, $15,30,45$, and 60 using a previously validated scale of zero to 10 where zero is no itching and 10 is extreme itching [51]. Itching scores of less than 3.5 are considered normal [51].

\section{Statistical methods}

Normal probability plots showed that dermatological scores performed by veterinarians (total score over the entire $\operatorname{dog}$ and for each of the 20 regions within each dog), percent change from baseline for the dermatological scores, age, and body weight were skewed. Accordingly, numerical data were summarized as medians with a range while categorical data (sex, breed, and final assessment [positive or negative]) were summarized as counts and percentages. Baseline prognostic factors were compared between diet groups using the Wilcoxon rank sum test (age and body weight) and Fisher's exact test (sex and breed).

Effects of diet (A vs B) and day (0 vs 30 vs 60 ) on the primary outcomes (total dermatological score and percent change in total dermatological core) were assessed using linear general estimating equations (GEE). Each of the linear models specified diet, day, and the interaction between diet and day as fixed effects. Correlations between observations within dog (the blocking factor) were modeled by specifying a compound symmetry covariance matrix. The interaction between diet and day was further analyzed (sliced) to extract comparisons between diets within each day and comparisons between days within each diet. $P$ values for 2 -way comparisons between days within diet were adjusted for multiple comparisons using Tukey's procedure.

For region specific dermatological scores (and their percent change from baseline), diet groups were compared within each day using the Wilcoxon rank sum test, while the days were compared within diet using Friedman's chi-square test. $P$ values for 2-way comparisons between days within diet were adjusted for multiple comparisons using Bonferroni's procedure. When computing percent change from baseline, a small value of 0.01 was added to each of the region-specific scores to avoid undefined values for dogs with a baseline value of 0 . An overall outcome of positive or negative was assigned to each dog when the study concluded. This outcome was compared between diet groups using Fisher's exact test. Statistical significance was set at $\alpha=0.05$. All analyses were performed using SAS version 9.4 (Cary, NC, USA).

\section{Abbreviations}

AD: Atopic dermatitis; Ig: Immunoglobulin; PUFA: Polyunsaturated fatty acid; DHA: Docosahexaenoic acid; EPA: Eicosapentaenoic acid; CADESI: Canine Atopic Dermatitis Extent and Severity Index.

\section{Authors' contributions}

Meyer and Becvarova: Conceptualization, Methodology, Writing - Review and editing. González Arribas: Conceptualization, Methodology, Funding Acquisition. Sánchez de Santiago, Moral Llamas: Investigation, Formal analysis, Writing - Original draft preparation. The author(s) read and approved the final manuscript.

\section{Funding}

This project was funded through Hill's Pet Nutrition.

\section{Availability of data and materials}

All data generated or analysed during this study are included in this published article [and its supplementary information files].

\section{Declarations}

Ethics approval and consent to participate

This prospective study complied with all relevant guidelines related to the use of animals in research in Europe, incl. Directive 2010/63/EU.

This prospective study was approved by the ethics committee of Complutense University.

All dog owners signed an informed consent form before entering this prospective study.

\section{Consent for publication}

N/A.

\section{Competing interests}

Iveta Becvarova and Hein Meyer are fully employed with Hill's Pet Nutrition, Inc. The Complutense University of Madrid Veterinary School received a study grant from Hill's Pet Nutrition, Inc. to support this study. Drs. Rollins and Werre received consultancy fees for their assistance with writing the manuscript and with the statistical analysis, respectively.

\section{Author details}

${ }^{1}$ Clinical Veterinary Hospital, Complutense University, Puerta de Hierro s/n, 28040 Madrid, Spain. ${ }^{2}$ Hill's Pet Nutrition Inc., 400 Southwest Eighth Avenue, Topeka, KS 66603, USA. 
Received: 11 March 2021 Accepted: 8 October 2021

Published online: 19 November 2021

\section{References}

1. Halliwell R. Revised nomenclature for veterinary allergy. Vet Immunol Immunopathol. 2006;114:207-8

2. Marsella R, Olivry T, Carlotti DN. Current evidence of skin barrier dysfunction in human and canine atopic dermatitis. Vet Dermatol. 2011;22:239-48.

3. Pucheu-Haston CM, Santoro D, Bizikova P, et al. Review: innate immunity, lipid metabolism and nutrition in canine atopic dermatitis. Vet Dermatol. 2015;26:104-e128.

4. Chermprapai S, Broere F, Gooris G, et al. Altered lipid properties of the stratum corneum in canine atopic dermatitis. Biochim Biophys Acta Biomembr. 2018;1860:526-33.

5. Olivry T, DeBoer DJ, Favrot $C$, et al. Treatment of canine atopic dermatitis: 2010 clinical practice guidelines from the international task force on canine atopic dermatitis. Vet Dermatol. 2010;21:233-48.

6. Logas D, Kunkle GA. Double-blinded crossover study with marine oil supplementation containing high-dose icosapentaenoic acid for the treatment of canine pruritic skin disease. Vet Dermatol. 1994;5:99-104.

7. Muller MR, Linek M, Lowenstein C, et al. Evaluation of cyclosporinesparing effects of polyunsaturated fatty acids in the treatment of canine atopic dermatitis. Vet J. 2016;210:77-81.

8. Saevik BK, Bergvall K, Holm BR, et al. A randomized, controlled study to evaluate the steroid sparing effect of essential fatty acid supplementation in the treatment of canine atopic dermatitis. Vet Dermatol. 2004;15:137-45

9. Mueller RS, Fieseler KV, Fettman MJ, et al. Effect of omega-3 fatty acids on canine atopic dermatitis. J Small Anim Pract. 2004;45:293-7.

10. Bensignor E, Morgan DM, Nuttall T. Efficacy of an essential fatty acidenriched diet in managing canine atopic dermatitis: a randomized, single-blinded, cross-over study. Vet Dermatol. 2008;19:156-62.

11. Schumann J, Basiouni S, Guck T, et al. Treating canine atopic dermatitis with unsaturated fatty acids: the role of mast cells and potential mechanisms of action. J Anim Physiol Anim Nutr (Berl). 2014;98:1013-20.

12. LeBlanc CJ, Horohov DW, Bauer JE, et al. Effects of dietary supplementation with fish oil on in vivo production of inflammatory mediators in clinically normal dogs. Am J Vet Res. 2008;69:486-93.

13. Inman AO, Olivry T, Dunston SM, et al. Electron microscopic observations of stratum corneum intercellular lipids in normal and atopic dogs. Vet Pathol. 2001;38:720-3.

14. Popa I, Pin D, Remoue N, et al. Analysis of epidermal lipids in normal and atopic dogs, before and after administration of an oral omega-6/ omega-3 fatty acid feed supplement. A pilot study. Vet Res Commun. 2011;35:501-9.

15. Shimada K, Yoon JS, Yoshihara T, et al. Increased transepidermal water loss and decreased ceramide content in lesional and non-lesional skin of dogs with atopic dermatitis. Vet Dermatol. 2009;20:541-6.

16. Reiter LV, Torres SM, Wertz PW. Characterization and quantification of ceramides in the nonlesional skin of canine patients with atopic dermatitis compared with controls. Vet Dermatol. 2009;20:260-6.

17. Magrone T, Jirillo E. Influence of polyphenols on allergic immune reactions: mechanisms of action. Proc Nutr Soc. 2012;71:316-21.

18. Singh A, Holvoet S, Mercenier A. Dietary polyphenols in the prevention and treatment of allergic diseases. Clin Exp Allergy. 2011;41:1346-59.

19. Niedzwiecki A, Roomi MW, Kalinovsky T, et al. Anticancer efficacy of polyphenols and their combinations. Nutrients. 2016;8(9):552.

20. Oz HS. Chronic inflammatory diseases and green tea polyphenols. Nutrients. 2017:9(6):561.

21. Zeinali M, Rezaee SA, Hosseinzadeh H. An overview on immunoregulatory and anti-inflammatory properties of chrysin and flavonoids substances. Biomed Pharmacother. 2017;92:998-1009.

22. Chung S-Y, Champagne ET. Reducing the allergenic capacity of peanut extracts and liquid peanut butter by phenolic compounds. Food Chem. 2009:115:1345-9.

23. Gong J, Chen S-S. Polyphenolic antioxidants inhibit peptide presentation by antigen-presenting cells. Int Immunopharmacol. 2003;3:1841-52.
24. Kim J-Y, Kina T, Iwanaga Y, et al. Tea polyphenol inhibits allostimulation in mixed lymphocyte culture. Cell Transplant. 2007;16:75-83.

25. Iwamura C, Shinoda K, Yoshimura M, et al. Naringenin chalcone suppresses allergic asthma by inhibiting the type-2 function of CD4 T cells. Allergol Intern. 2010;59:67-73.

26. Tomita M, Irwin KI, Xie ZJ, et al. Tea pigments inhibit the production of type $1(\mathrm{~T}(\mathrm{H} 1))$ and type $2(\mathrm{~T}(\mathrm{H} 2))$ helper T cell cytokines in CD4(+) T cells. Phytother Res. 2002;16:36-42.

27. Zuercher AW, Holvoet S, Weiss M, et al. Polyphenol-enriched apple extract attenuates food allergy in mice. Clin Exp Allergy. 2010;40:942-50.

28. Kawai K, Tsuno NH, Kitayama J, et al. Catechin inhibits adhesion and migration of peripheral blood B cells by blocking CD11b. Immunopharm Immunot. 2011:33:391-7.

29. Yano S, Umeda D, Maeda N, et al. Dietary apigenin suppresses IgE and inflammatory cytokines production in C57BL/6N mice. J Agric Food Chem. 2006;54:5203-7

30. Kanoh R, Hatano T, Ito H, et al. Effects of tannins and related polyphenols on superoxide-induced histamine release from rat peritoneal mast cells. Phytomedicine. 2000;7:297-302.

31. Scheller S, Dworniczak S, Pogorzelska T, et al. Effect of quercetin, caffeic acid and caffeic acid phenylethyl ester, solubilized in non-ionic surfactants, on histamine release in vivo and in vitro. Arzneimittelforschung. 2000;50:72-6.

32. Pearce FL, Dean Befus A, Bienenstock J. Mucosal mast cells. J Allergy Clin Immunol. 1984;73:819-23.

33. Finn DF, Walsh JJ. Twenty-first century mast cell stabilizers. Br J Pharmacol. 2013;170:23-37.

34. Sivaranjani N, Rao SV, Rajeev G. Role of reactive oxygen species and antioxidants in atopic dermatitis. J Clin Diagn Res. 2013;7:2683-5.

35. Kapun AP, Salobir J, Levart A, et al. Oxidative stress markers in canine atopic dermatitis. Res Vet Sci. 2012;92:469-70.

36. Jaffary F, Faghihi G, Mokhtarian A, et al. Effects of oral vitamin E on treatment of atopic dermatitis: a randomized controlled trial. J Res Med Sci. 2015;20:1053-7.

37. Plevnik Kapun A, Salobir J, Levart A, et al. Vitamin E supplementation in canine atopic dermatitis: improvement of clinical signs and effects on oxidative stress markers. Vet Rec. 2014:175:560.

38. Shin J, Kim YJ, Kwon O, et al. Associations among plasma vitamin C, epidermal ceramide and clinical severity of atopic dermatitis. Nutr Res Pract. 2016;10:398-403

39. Leveque $N$, Robin $S$, Muret $P$, et al. High iron and low ascorbic acid concentrations in the dermis of atopic dermatitis patients. Dermatology. 2003:207:261-4.

40. Jewell D, Gross K, Bendar G, et al. Polyphenols affect cytokines and when included in a food with enhanced fatty acids and antioxidants reduce skin erythema in dogs with atopic dermatitis. In: 11th world congress on polyphenols applications: Vienna polyphenols; 2017

41. Witzel-Rollins A, Murphy M, Becvarova I, et al. Non-controlled, openlabel clinical trial to assess the effectiveness of a dietetic food on pruritus and dermatologic scoring in atopic dogs. BMC Vet Res. 2019:15:220.

42. Olivry T, Saridomichelakis M, Nuttall T, et al. Validation of the Canine Atopic Dermatitis Extent and Severity Index (CADESI)-4, a simplified severity scale for assessing skin lesions of atopic dermatitis in dogs. Vet Dermatol. 2014;25(77-85):e25.

43. National Research Council. Nutrient requirements of dogs and cats. Washington, D.C.: The National Academies Press; 2006.

44. Karuppagounder V, Arumugam S, Thandavarayan RA, et al. Molecular targets of quercetin with anti-inflammatory properties in atopic dermatitis. Drug Discov Today. 2016:21:632-9.

45. Shen $Y, X u J$. Resveratrol exerts therapeutic effects on mice with atopic dermatitis. Wounds. 2019:31:279-84.

46. Hensel P, Santoro D, Favrot C, et al. Canine atopic dermatitis: detailed guidelines for diagnosis and allergen identification. BMC Vet Res. 2015;11:196.

47. Herchi W, Arráez-Román D, et al. Phenolic compounds in flaxseed: a review of their properties and analytical methods. An overview of the last decade. J Oleo Science. 2014;63:7-14.

48. Rhodes DH, Hoffmann L, Rooney WL, et al. Genome-wide association study of grain polyphenol concentrations in global Sorghum 
[Sorghum bicolor (L.) Moench] germplasm. J Agric Food Chem. 2014;62:10916-27.

49. Pérez-Jiménez J, Neveu V, Vos F, et al. Identification of the 100 richest dietary sources of polyphenols: an application of the phenol-explorer database. Eur J Clin Nutr. 2010;64:S112.

50. Tan BL, Norhaizan ME. Scientific evidence of rice by-products for cancer prevention: chemopreventive properties of waste products from rice milling on carcinogenesis in vitro and in vivo. Biomed Res Int. 2017:2017:9017902
51. Rybnicek J, Lau-Gillard PJ, Harvey R, et al. Further validation of a pruritus severity scale for use in dogs. Vet Dermatol. 2009;20:115-22.

\section{Publisher's Note}

Springer Nature remains neutral with regard to jurisdictional claims in published maps and institutional affiliations.
Ready to submit your research? Choose BMC and benefit from:

- fast, convenient online submission

- thorough peer review by experienced researchers in your field

- rapid publication on acceptance

- support for research data, including large and complex data types

- gold Open Access which fosters wider collaboration and increased citations

- maximum visibility for your research: over $100 \mathrm{M}$ website views per year

At BMC, research is always in progress.

Learn more biomedcentral.com/submissions 